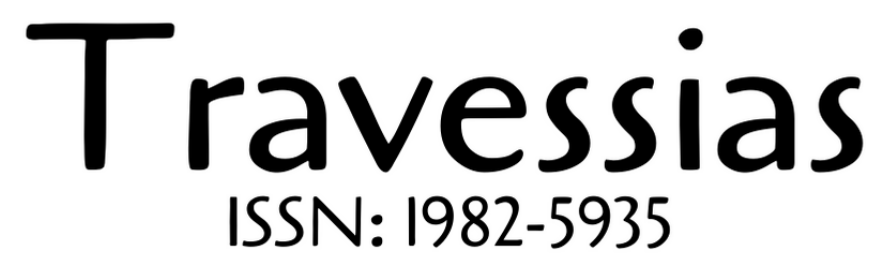

\title{
CORINGA E O RETRATO DE UM VILÃO CRIADO PELA SOCIEDADE
}

\author{
Anna Karolyne Resende Vilar Araujo - annakarolyne.vilar@yahoo.com.br \\ Faculdade de Ciências Biomédicas de Cacoal, Facimed, Cacoal, Rondônia, Brasil; \\ https://orcid.org/0000-0002-4549-736X
}

\begin{abstract}
RESUMO: Esse trabalho é uma resenha crítica do filme Coringa (2019) com direção e produção de Todd Phillips. O filme retrata a história de um adulto em sofrimento com o caminho de sua vida e com problemas de saúde mental. $\mathrm{O}$ personagem possui dificuldades de se inserir na sociedade após um tempo recluso no manicômio, o sistema não o ajuda e ele se vê completamente sozinho, a margem da sociedade. A reviravolta acontece com a ascensão do mesmo de um simples palhaço maltratado no emprego para um vilão nitidamente desequilibrado que se torna símbolo da revolta popular contra governantes políticos. Buscou-se analisar os distúrbios mentais existentes do personagem Coringa e a crítica recorrente que o filme faz ao funcionamento da sociedade em relação aos doentes mentais e suas desordens. Trata-se de uma pesquisa de cunho exploratório, tendo como embasamento para discussão a teoria da Psicanálise e sua base bibliográfica. Nutrindo como principais resultados as discussões acerca dos transtornos mentais existentes do personagem e o relapso ao sistema de saúde.
\end{abstract}

PALAVRAS-CHAVE: Psicopatia; Esquizofrenia; Doença Mental.

CORINGA. Direção: Todd Phillips. Produção de Village Roadshow Pictures. Estados Unidos: Warner Bros, 2019. 1 DVD.

\section{INTRODUÇÃO}

O artigo tem como objetivo a busca dos conceitos da psicanálise e de como são utilizados no enredo do filme Coringa (2019). Buscando entendimento sobre os transtornos mentais do protagonista que não são claros o suficiente para os espectadores e assim procura uma reflexão acerca do ser humano por trás dos transtornos mentais e suas possíveis causas e desordens.

Coringa é um personagem dos quadrinhos sendo o principal arqui-inimigo do herói Batman, foi criado e teve sua primeira aparição em 1940 na revista do Batman pela editora DC Comics, onde a loucura é entendida como seu principal poder. Quase depois de 80 anos de sua criação e ele é considerado por muitos críticos e leitores o maior vilão das revistas em quadrinho, proporcionando grandes mudanças na literatura desse gênero. $O$ filme desperta a curiosidade sobre possíveis transtornos mentais do personagem e embarca em uma crítica um tanto quanto encoberta sobre a política e o modo como é tratado os doentes mentais na sociedade, assim levando ao telespectador a refletir sobre a vida do protagonista. 


\section{O ENREDO}

Arthur Fleck é o verdadeiro nome do Coringa. O filme retrata sua vida pós internação no manicômio Arkham e mostra suas visitas a assistente social onde vai para falar sobre seu dia-a-dia, isso leva a um retrato do serviço público carente ofertado a pessoas com transtornos mentais e a falta de profissionais qualificados, já que está claro nos diálogos do filme que a assistente social parece não compreender os devaneios e os sentimentos do personagem, e não demonstra se importar em ajuda-lo realmente. Quando a assistente social relata que os encontros serão finalizados pelo motivo de cortes de verbas, é citado que o governo não liga para pessoas como o protagonista, ou seja, doentes mentais, pois não sabe o que fazer com esses indivíduos quando realocados novamente em sociedade. Podemos associar esse treco com o corte de verbas do CAPS (Centro de Atenção Psicossocial) no Brasil que é voltado a cuidar de pessoas com doenças mentais, que deixaram cerca de 319 unidades desatendidas de profissionais qualificados e amparo a pessoas com transtornos mentais que dependem do governo (PINHEIRO, 2018).

\section{O CORINGA E A PSICANÁLISE}

A risada é uma das características principais desse vilão. O filme tem seu princípio induzindo o telespectador a pensar que seja um distúrbio em decorrência de um dano cerebral que o personagem principal Coringa sofreu na infância pelos maus tratos da mãe e do namorado desta, porém logo a frente ele relata que não ri em decorrência do distúrbio e sim porque quer, ou seja, fica a dúvida se pode ser tanto um mecanismo de defesa do ego, que se acordo com Klein (1982) se inicia nos primeiros anos da infância assim como o do protagonista. É uma psicose que obriga o ego a desenvolver mecanismos específicos de defesa que são processos subconscientes realizados pela personalidade, que ajuda a mente nos processos que podem gerar ansiedades, hostilidades, frustações não resolvidas a modo conscientes (SILVA, 2011). A Questão não é solucionada no filme então fica a curiosidade se as risadas presentes nas situações que ele se sente nervoso/pressionado são de fato uma lesão cerebral que veio a prejudicá-lo nesse aspecto.

Arthur apresenta traços de psicopatia que é considerado um dos transtornos de personalidade, pois psicopatas são entendidos como indivíduos frios, inaptos para manter relacionamentos, pessoas com baixa tolerância à frustração, tendência a agressividades, sem sentimento de culpa, assim dizendo, eles não sentem remorso com as mortes que causam e sim um alívio, o personagem sente esse alívio quando mata pela primeira vez (DA SILVA,2015). Entretanto na abordagem Freudiana, não se usa o termo 
psicopatia, e sim, perversão - que é dividida em vários tipos - que, de acordo com Freud (1916), a perversão é um tipo específico de estruturação subjetiva, de desejo e fantasia.

Um dos grandes motivos de conflitos para o personagem é a relação conturbada com a mãe, apesar de ser o cuidador da mesma. Fica claro na história que a mãe tem distúrbios mentais que acaba por influenciar no modo de criação do filho, e não apresenta afetividade declarada pelo mesmo. A busca de Coringa pelo seu pai evidencia a carência de afeto que o mesmo tem, pois, como dito pelo mesmo, ele estava em busca de um abraço do pai, porém descobre a mentira da mãe sobre sua origem e isso o deixa transtornado.

Quando Arthur descobre a mentira sobre sua origem ele mata a mãe com uma tranquilidade que não pode ser entendida como normal e além disso psicopatas podem infringir leis para obter o que querem e assim se torna importante a precisa identificação do mesmo (SUECKER, 2005; LEWIS, 2005). Porém é importante lembrar que nenhuma punição é capaz de fazer com que o psicopata mude suas maneiras e modos, apesar de que as práticas de punição, de ordem médica e jurídica, sejam as que mais recaiam sobre os indivíduos com esse transtorno (SHINE, S. K, 2000).

Para a psicanálise desde 1896 quando foi elaborada a primeira teoria do aparelho psíquico, um indivíduo deve estruturar-se psiquicamente como neurótico, psicótico ou perverso, as diferenças de estruturas são inconscientes (FREUD, 1916). Coringa pode ser classificado dentro da psicose com os sintomas de alucinação, confusão de pensamentos e a presença do transtorno da esquizofrenia que é uma das subdivisões da psicose. Além de apresentar traços psicóticos e esquizofrênicos, Coringa apresenta sintomas de depressão como sentimento de tristeza, irritabilidade e agressividade (FU I; CURATOLO; FRIEDRICH, 2000). Os sintomas depressivos podem interferir na ressocialização de um doente mental e na maneira como ele percebe o mundo ao seu redor.

Arthur se transformou no Coringa utilizando sua maquiagem de palhaço como uma espécie de casulo onde assim ele poderia ser quem verdadeiramente queria, já que quando preso no manicômio este ficou à mercê de terceiros. O processo de exclusão social foi imposto pela hospitalização em asilos; pelo aparecimento da psiquiatria, que passou a considerar os tutores dos considerados insanos e incapazes do convívio social e com isso afastando os pacientes da sociedade (SZAZZ,1978).

Durante o filme é mostrado em muitas cenas os pensamentos delirantes de Arthur e outros sintomas típicos da esquizofrenia paranoide que se caracteriza pela presença de ideias delirantes, em geral acompanhadas de alucinações e de perturbações das percepções. No filme Arthur se imagina em um relacionamento com a sua vizinha, porém isso não era real, assim como na sua apresentação de stand-up onde ele pensou que estava fazendo sucesso, entretanto a plateia não gostou dele. A esquizofrenia paranoide é um transtorno de longa duração no qual o indivíduo experimenta períodos de crises e remissões que resultam em deterioração do funcionamento do doente, causa muitos danos e perdas nas 
habilidades para se relacionar individual e socialmente e para manter pensamentos completos, onde ele demonstra em várias cenas sua dificuldade de se relacionar em sociedade (NETO; LEMES; PEDERZOLI; HERNANDES, 2011).

\section{CONSIDERAÇÕES FINAIS}

Coringa é um retrato real da sociedade atual. Mesmo se passando a alguns anos atrás, consegue captar a essência de um doente mental psicótico e esquizofrênico e de como a sociedade com seu descaso o ajudou a se transformar em um assassino. O palhaço se torna um símbolo das manifestações por melhorias na cidade, mesmo ele admitindo em rede nacional ser um assassino. A verdade é que Arthur simplesmente foi o espelho das pessoas que se viram retratas ali, na quele personagem que dê um modo errôneo, enfrenta os políticos, relata os erros da sociedade e o descaso com os mais necessitados.

Os pontos apresentados no artigo vão de encontro com a teoria psicanalítica, como ela pode ser empregada e embasada no enredo do filme e de como o personagem principal é um resultado da sociedade que ele vive. Além da sua doença mental, o filme não classifica os transtornos de Arthur, não se prendem a rótulos e é exposto seus sintomas, mas nunca um diagnóstico conciso, isso vai da imaginação do telespectador. O indivíduo é produto da sociedade e do meio em que vive. Se a sociedade favorece a reintegração as chances de ter sucesso serão maiores, mas se a sociedade reprime o indivíduo ele se voltará contra ela.

\section{REFERÊNCIAS}

DA SILVA, Jordan Prazeres Freitas. A Psicopatia a partir da Psicanálise: desmistificando a visão da mídia. Mneme-Revista de Humanidades, v. 16, n. 37, p. 72-90, 2015.

FREUD, Sigmund. Neurose, psicose, perversão. Autêntica, 1916.

FREUD, S. Mal-estar na civilização (1929-1930). Obras Psicológicas Completas de Sigmund Freud. Rio de Janeiro: Imago, 1996. Edição Standard Brasileira, v. 21, p. 73-150.

FU I. L., CURATOLO, E., \& FRIEDRICH, S. (2000). Transtornos afetivos. Revista Brasileira de Psiquiatria, 22, 24-27.

KAPLAN, H. B.; SADOCK, B. J.; GREBB, J. A. Compêndio de psiquiatria: Ciências do comportamento e psiquiatria clínica. Porto Alegre: Artes Médicas, 2003.

KLEIN, M. Notas sobre alguns mecanismos esquiroides. In: KLEIN, M. Os progressos na psicanálise. Rio de Janeiro. Guanabara, 1982. p. 314-343.

LEWIS, D. Sociopatia: transtorno e delinqüência. Direito e Justiça, v. 31, n. 2, p. 25- 40. 2005. 
NETO, F. K., LEMES, C. F., PEDERZOLI, A. A.; HERNANDES, M. L. A. DSM e psicanálise: uma discussão diagnóstica. Revista da SPAGESP, v. 12, n. 2, p. 44-55, 2011.

PHILLIPS,T., COOPER,B., TILLINGER,E. (Producers), \& PHILLIPS,T. (Director). (2019). Coringa [Film]. Estados Unidos da América: Warner Bros. Entertainment.

PINHEIRO,L. (2018,19 de Novembro). Ministério da saúde suspende quase R\$78 milhões em repasses para atendimento à saúde mental. G1. Disponível em https://g1.globo.com/ciencia-esaude/noticia/2018/11/19/ministerio-da-saude-suspende-quase-r-78-milhoes-em-repasses-paraatendimento-a-saude-mental.ghtml

SILVA, Cristina Martins Cunha da et al. Compreender para intervir: um estudo sobre a prática alienativa nas varas de família. 2011.

SHINE, S. K. Psicopata. Rio de Janeiro: Casa do Psicólogo, 2000.

SUECKER, B. Sociopatia: transtorno e delinquência. Direito e Justiça, v. 31, p. 25-40. 2005.

SZAZZ, T. A fabricação da loucura: um estudo comparativo entre a inquisição e o movimento da saúde mental. Rio de Janeiro: Zahar, 1978. 


\title{
Title
}

Joker and the portrait of a villain created by society.

\begin{abstract}
This is a review of the film Joker (2019) with direction and production by Todd Phillips. The film portrays the story of an adult in distress with the path of his life and with mental health problems. The character finds it difficult to insert himself into society after a time spent in the asylum, the system does not help him and he finds himself completely alone, on the margins of society. The turnaround comes with the rise of a simple badly treated clown on the job to a clearly unbalanced villain who becomes a symbol of popular revolt against political rulers. We sought to analyze the existing mental disorders of the character Joker and the recurring criticism that the film makes to the functioning of society in relation to the mentally ill and their disorders. This is an exploratory research, based on the discussion of the theory of Psychoanalysis and its bibliographic base. Nourishing as main results the discussions about the existing mental disorders of the character and the relapse to the health system.
\end{abstract}

\section{Keywords}

Psychopathy; Schizophrenia; Mental disease.

Recebido em: 02/11/2020.

Aceito em: 09/04/2021. 